\title{
Designing Functional Virtual Learning Communities Using the Bola Ola Method
}

\author{
Bolanle A. Olaniran* \\ Department of Communication Studies \\ Texas Tech University, USA \\ E-mail: B.Olaniran@ttu.edu \\ *Corresponding author
}

\begin{abstract}
This paper explores how social media and the likes of Web 2.0 are gaining ground in e-learning and virtual communities. The paper argues that successful learning in virtual learning communities (VLCs) require cultural sensitivity given that technological tools in these communities were not originally designed for learning. The paper uses the dimensions of cultural variability to identify some of the cultural challenges in VLCs. Subsequently, the Bola Ola method is presented as a way to address cultural challenges and effective use of VLCs. Finally, implications are presented as well.

Keywords: Virtual Learning Community; E-Learning; Information Communication Technologies; Web 2.0; Social Media; Decision-Making Stages; Idea Generation; Evaluation; Culture

Biographical notes: Bolanle A. Olaniran is a professor in the Department of Communication Studies at Texas Tech University. His research includes eLearning, organization communication, crisis communication, cross-cultural communication, and technologies. He has authored several peer reviewed articles in discipline focus and interdisciplinary focus journals (i.e., regional, national, and international) and several edited book chapters in each of these areas. He has served as a consultant to organizations and universities at local, national, international and government levels.
\end{abstract}

\section{Introduction}

We are living in an information-rich digital age where knowledge and information explosions are a constant reality. Thus, information technologies offer more potential possibilities than originally imagined. Emerging Web 2.0 technologies, characterized by social networking, provide information sharing and collaboration among users through content generation and development along with knowledge in virtual learning communities (VCLs) (Bonk, 2009).

At the same time, the demand for education and knowledge management necessitates an environment in which training is not confined to a particular locale but rather to virtual communities where portability, mobility, and convenience are important (Olaniran, 2009). A VLC is broadly defined as both informal, such as one that supports ongoing professional development, and formal, like those in a traditional course setting lasting a semester. Accordingly, information communication technologies (ICTs) and VLCs have enabled knowledge dissemination to the extent that organizations are 
increasingly taking leadership roles in their training needs to prepare potential workers for continued professional development (Olaniran \& Agnello, 2008; Rao, 2011; Stewart \& Kagan, 2005).

The emergence of Web 2.0 consists of social networking sites, blogs, wikis, video sharing sites, virtual worlds, digital storage, and repositories that allow individuals to develop VLCs for subjects (Hossain \& Aydin, 2011). These emerging technologies have provided opportunities for developing virtual communities where learning, instruction, and professional development take place in innovative, creative, and engaging-albeit alternative to traditional-learning environments. Notwithstanding, these Web 2.0 technologies have offered opportunities to enhance training in primary, secondary, and tertiary institutions while also providing different non-traditional institutions and corporate organizations ways to customize their learning and training requirements (Olaniran, 2009; Rao, 2011).

The potential for emerging Web 2.0 technologies has not been fully recognized or tapped since critical challenges remain that must be resolved One area of challenge is the need for cultural sensitivity regarding social media and networking applications developed for purposes other than formal education applications. Also, some technologies surrounding social media are developed for a particular culture but are applied across multiple cultures and contexts (Economides, 2008). Therefore, it is the goal of this paper to present some of the cultural challenges and, in particular, to address the issue of control in the application of social media in VLCs. This will be accomplished by presenting the Bola Ola Method, which is a two-stage (i.e., idea generation and evaluation) process of decision-making (e.g, Fisher, 1980; DeSanctis \& Poole, 1994; Olaniran. 1994) that uses VLCs and accompanying social media for achieving culturally appropriate learning.

Perhaps one of the biggest shifts from the traditional learning environment to VLCs is the fact that learners are considered more proactive than passive learners and, as such, they take an active role and greater control in the way they learn or co-create knowledge. To this end, teachers in e-learning communities are considered facilitators such as guides, coaches, and mentors rather than sole providers of knowledge. Teachers are no longer at the center of learning; rather, they are considered another piece of many informational sources available to students in the learning communities (Olaniran \& Williams, 2010). This assertion is rooted in the constructivist ideology which holds that the best way to teach is to make the learning process self-reflexive for learners and for learners to take increased control in how they learn (e.g., Biech, 2008; Gamble, 2009; Shepard, 2010). Unfortunately, the constructive ideology fails to take into account the fact that national culture dimensions play a significant role in learning online. Scholars have examined the different roles culture plays in learner preferences (e.g., Edmundson, 2009; Nathan, 2008; Olaniran, 2009; Rodrigues, 2005). Given the need for cultural sensitivity in VLCs, the next section will examine culture using the dimensions of cultural variability provided by Geert Hofstede. From the dimensions, an attempt will be made to articulate the issue of control, which is germane to learning in VLCs and their design.

\section{Dimensions of Culture and VLCs}

Culture has significant implications for the adoption of Web 2.0 technologies and innovations in general. From this standpoint, it is helpful to examine the dimensions of cultural differences to understand exactly how culture impacts the use of technology and 
learning in VLCs. One model of culture includes the dimensions of cultural variability (Hofstede, 1980). There are four dimensions of cultural variability: power distance, uncertainty avoidance, individualism, and masculinity (Hofstede, 1980; 2001; see also Dunn \& Marinetti, 2002; Olaniran, 2007for overviews of cultural value orientations and cultural dimensions). More than arbitrary categories of culture, these four dimensions result from data collected from 50 countries and three world regions (Hofstede, 1980; 1983). Past research has used these dimensions to operationalize cultural differences and their effects on intercultural communication interactions (Gudykunst, Chua, \& Gray, 1987; Olaniran \& Stewart, 1996; Roach \& Olaniran, 2001; Sanchez-Franco, MartinezLopez, \& Martin-Velicia, 2009). Though dated, this has been the subject of criticism (Ess \& Sudweeks, 2005; McSweeney, 2002). Nevertheless, support for the dimension have withstood the test of time (see Ess \& Sudweeks, 2005, for a summary of studies). Furthermore, Smith (2002) argues that McSweeney ignored "almost entirely" the actual overall pattern of Hofstede's results by focusing only on two countries whose behaviors did not follow expectations. Even in an attempt to come up with a better model, such as the GLOBE cultural study (Chhokar, Broidbeck, \& House, 2007) that was perceived to be more comprehensive than Hofstede's, the four dimensions were upheld within the GLOBE's nine cultural dimensions (see also Rao's 2011 review of the GLOBE study). In essence, Hofstede's dimension provides a general and useful approach to operationalizing culture.

Power distance focuses on "the extent to which the less powerful members of institutions and organizations accept that power is distributed unequally" (Hofstede \& Bond, 1984, p. 418). Uncertainty avoidance describes "the extent to which people feel threatened by ambiguous situations and have created beliefs and institutions that try to avoid these" (Hofstede \& Bond, 1984, p. 419). Of these dimensions, the most frequently discussed, when it comes to culture and virtual learning is the individualistic/collectivistic dimension (Tapanes, Smith, \& White, 2009). Individualism-collectivism acknowledges the fact that in individualistic cultures, "People are supposed to look after themselves and their family only," while in collectivistic cultures, "People belong to in-groups, or collectivities, which are supposed to look after them in exchange for loyalty" (Hofstede \& Bond, 1984, p. 419). The masculinity dimension addresses cultures in which "dominant values in society are success, money and things," while femininity refers to cultures "in which dominant values are caring for others and quality of life" (Hofstede \& Bond, 1984, p. 419-420). All of these dimensions have been directly linked to e-learning (Olaniran, 2007). Furthermore, it is accepted that the cultural motivations of individuals play a significant role while representing the foundation of e-learning (Henning, 2003; Schneckenberg, 2009; Van Dam \& Rogers, 2002).

Using Hofstede's (1980) dimensions of cultural variability, Van Dam and Rogers (2002) discuss design elements and actions for the adaptation of e-learning and general adoption of technologies. Within the uncertainty avoidance dimension, e-learning issues of security and risk are the primary concern (see also Tapanes, Smith, \& White, 2009). For instance, e-learning is expected to be seen in high-risk tolerance countries (i.e., culture) as something intriguing and potentially fun, motivational, and interesting; in high-security (i.e., low-risk tolerance) cultures it can be perceived as dangerous or downright risky. Power distance, which is a measure of inequality in a given culture, suggests that in high-equality cultures, concerns arise as to the expectations that knowledge is being shared or distributed equally. In a high-status culture, however, expectations call for "telling" strategies where the knowledgeable are expected to teach whatever is needed to be learned (see also Sanchez-Franco et al., 2009; Olaniran \& 
Agnello, 2008) where experts or teachers are expected to help facilitate learning (Rao, 2011).

Specifically, Lee and Johari (2004) examine web-based instruction (WBI) use in China (i.e., a high-power distant culture) and note that the web introduces a Westernized, liberal democratic method of communication, which in essence biased users toward these sets of values (see also Tapanes et al., 2009; Thurber, Pope, \& Stratton, 2003). Individualism then suggests that in a high independence culture, there is a sense of controlling one's destiny regarding career and work choices. But in a collectivistic culture (i.e., group-oriented), the success of the group is more important. The masculinefeminine dimension describes the idea of work-life balance in which work-focused countries require achievement and recognition (i.e., people live to work), whereas in a life-focused culture, work-related issues including learning must be performed within the context of life (i.e., people work to live).

Despite opportunity for increased participation facilitated in Web 2.0 technologies and VLCs in certain cultures, most cultures still remain high-context and power distant (i.e., Japanese culture). In a high-context culture, information is internalized in persons or situations, while power distant cultures recognize the fact that power is not evenly distributed (see Hall, 1976; Hofstede, 1980). These cultural categories have implications for implicit and explicit communication tendencies and the general propensity to use technology in global education and e-learning (see also Olaniran, 2009; Rao, 2011). For instance, Chinese students "are more silent, passive, diligent, formal, and contentoriented in discussions; deferent to teachers; have concern for others; and worry about losing face" (Zhu, Valcke, Schellens, 2009, p. 34). Zhu et al. (2009) noted Western cultures generate very different educational philosophies and beliefs in comparison to Asian cultures, which can affect the acceptance of WBI technology. Therefore, cultural factors tend to influence VLCs in terms of how individuals use and respond to communication technologies and the interpretations drawn from messages distributed through them. Devereaux and Johansen (1994) argued that it might be difficult to get people to use certain technologies such as computer-mediated communication (CMC) systems in power distant cultures where status dictates every aspect of interpersonal communication.

Technology transfer, the likes of Web 2.0 technologies, are not value free but intrinsically value laden (Aydin, McIsaac, \& Johari, 2004; Lee \& Johari, 2004; Olaniran \& Williams, 2010; Thurber, et al., 2003). At the same time, other scholars (e.g., Ess, 2002) have argued for the soft deterministic effect of technology, which implies that every culture tends to find ways to adapt technologies to their cultural communication, though none dispute the fact that cultural differences affect technology adoption and use. For instance, in African cultures, where significant emphasis is placed on relationships, it was found that when e-mail was used for local communication, users often follow online communication with a telephone call as a back-up medium to ensure that the message had been received (McConnell, 1998, Olaniran, 2007). Japanese technology designers acknowledged the issue of culture by indicating that not all types of communication can be supported by communication technology. Heaton (1998) argued that a familiar sense of atmosphere and feeling must be conveyed for communication technologies to be useful in Japan. Therefore, Heaton (1998) recommends that online groups and communities ought to meet first face-to-face to establish a trust environment. This technology assessment may explain the disparity in technology use for e-learning where 60 percent of U.S. multinational organizations were reported to actively promote e-learning for employee training versus 7 percent for Japan (Reynolds, 2008). 
In general, a key challenge in VLCs indicates that there does not appear to be a technological or cultural fit in the diffusion of some westernized technologies (e.g., Green \& Ruhledder, 1995; Mesdag, 2000; Olaniran, 2007; 2009). Specifically, learning content in Web-based environments needs to match the needs of users. Olaniran (2009) argues that "effort must be focused to ensure that all learners have their needs met, and more importantly, that learning takes place" (p. 269). Rarely do technologies powering Web 2.0 or VLCs resolve cultural challenges including differences in values and structures such that learning activities and goals may fail (see also Khalil \& Seleim, 2009; Zhu et al., 2009; Olaniran, 2009). However, learning theories suggest that learning and knowledge is dependent on how individuals are culturally and socially trained or predisposed (Biech, 2008; Nathan, 2008; Olaniran \& Agnello, 2008; Rao, 2011). Consequently, deliberate effort by instructors is needed to address cultural sensitivity in e-learning within VLCs beyond mere awareness of these differences. One way of doing this is to focus on issues of control relating to whether learning ought to be in the hands of learners or teachers. Similarly, the power distance dimension is useful in navigating control.

\section{Addressing Control in Web 2.0}

Olaniran \& Williams (2010) address the issue of control and, in particular, transactional control in Web 2.0 extensively. One of the general arguments in favor of incorporating newer communication technologies into education and learning curricula is the fact that technologies enhance learners' capacity to determine how they learn (Olaniran, Savage, \& Sorenson, 1996). Similar arguments have been made about e-learning as one of the major reasons for using Web 2.0 in learning (Dron, 2007).

The notion of control in a learning environment, particularly in VLCs, extends to the identified cultural effect. For instance, in high-power distance cultures, learners prefer a teacher-centered method of learning where teachers are identified as experts and are thus afforded the appropriate status power of directing how students learn and what they learn (Nathan, 2008; Olaniran \& Agnello, 2008; Rao, 2011). The approach to learning and the influence of culture on learning is established early on and subsequently reinforced over time for developing learning preferences and patterns among learners (Rao, 2011). On the other hand, learners from low-power distant or individualistic cultures, do not hold the same beliefs as those in high-power distance cultures. Learners then would instead cherish the opportunity to take an active role in learning and may welcome the opportunity to share new or superior knowledge with their trainers or teachers. Hence, the self-paced and individually oriented structure of e-learning in VLCs may be more appealing.

The negotiation of control in VLCs is one that has not been fully explored in Web 2.0 and online learning communities. The idea of control in Web 2.0 learning environments becomes important because it subscribes to the constructivists' ideology of allowing students to have increased control in how they choose to learn. According to constructivists, how learners choose to learn is believed to be a direct consequence of the level of choice they are given in learning (Olaniran \& Agnello, 2008). For example, Jarvis (2000) talks about futuristic learning where a society, in an attempt to meet the requirements of global learning needs, stresses the idea that knowledge is fostered through the use of technologies and computers and, when developed, is a way to provide equal opportunities for every individual to receive as much education as they are believed to be capable of. However, it appears that the educational community accepts this notion 
as a fact without challenge regardless of whether it is in traditional offline or virtual learning environments (Olaniran \& Williams, 2010). At the center of the need to critically examine constructivists' claims is whether and how students are capable of learning on their own, especially when teachers are relegated to facilitating roles as well as how they negotiate transactional control. Furthermore, it stands to question whether technologies can effectively perform or substitute for teachers in learning environments based on different cultural learning preferences. In essence, emphasis must be placed on how to best accomplish the goal of providing learners adequate control in a manner that fosters their cultural learning styles without negatively impacting their ability and motivation to learn.

\section{Solutions and Recommendations}

All in all, Web 2.0 environments still may be able to provide rich communities for learning in spite of the challenges provided above. However, to ensure success, designers would need to be cognizant of these challenges and design virtual learning spaces in such a way to help overcome some of the potential pitfalls (Olaniran, 2007; Varela de Freitas \& Valente, 2001). For example, there is a need to allow instructors to design learning experiences in VLCs in a manner that helps accommodate and is sensitive to learners' cultural and learning preferences. Such aim will also help in navigating the issue of control presented in this paper. To do this, the author proposes the idea of the Bola Ola method introduced earlier. The Bola Ola method attempts to describe or categorize elearning as involving key decision-making steps that instructors contemplating using VLCs can use as a systematic tool that helps prepare them and their students for a well structured and culturally appropriate use of technology in a learning space. The Bola Ola method is a two-stage decision process that was introduced and has been empirically tested for incorporating technology into collaborative or group decision-making processes (Olaniran, 1994). The approach is rooted in decision-making models that other scholars have used to evaluate interaction in traditional or electronically mediated environments (e.g., DeSanctis \& Poole, 1994; Fisher, 1980). The two-stage model consists of idea generation and evaluation and represents two distinct phases that groups generally experience in problem-solving or decision-making.

The two stages were formed by the vigilant interaction theory (VIT) (Gouran \& Hirokawa, 1983; Hirokawa \& Rost, 1992). The idea generation stage deals with attempting to analyze problems, determining the goals, and generating possible solutions to the problem. On the other hand, the evaluation stage focuses on establishing key criteria for evaluating ideas, discussing implications of possible decisions, and selecting solutions for the problem (Olaniran, 1994). The VIT perspective is useful because it offers guidelines for creating effective learning.

\subsection{Idea Generation Stage}

The idea generation stage is similar to the planning stage for online instructors. In particular, this stage is characterized by thinking out of the box where an instructor planning to utilize Web 2.0 tools must take the time to identify specific goals regarding course content or skills that learners must accomplish upon completion of the curriculum. During the idea generation stage, the instructor would need to engage in brainstorming activities where emphasis is given to ideas that would help bring students to achieve course goals or transformative learning mode. In order to accomplish this, it is important to engage in brain writing where ideas are written down to safeguard against memory loss 
or forgetfulness. It is also important to engage services of other educators or teachers, such as learning centers or professional development and technology learning centers, to identify what is feasible and what is not. The process of running the idea by other scholars would help facilitate creativity in ideas and thinking to determine that nothing is left to chance. Part of the process involves identifying who the learning audience and/or participants are in terms of their cognitive and socio-cultural needs as described above. Who are the students? What information do they have? What are their backgrounds? These questions need to be answered. Furthermore, the idea generation mode should also devote a significant amount of time and energy to identifying which technology platforms hold the best chance for accomplishing the identified goal (i.e., asynchronous or synchronous) (e.g., Olaniran, 2006; Rao, 2011). The whole purpose of the idea generation stage must be about how to facilitate knowledge learning in the VCLs and cooperatives. The idea generation process for the most part puts control in the hands of the instructors, but this is not to say flexibility in negotiating Web tools and technologies with learners cannot be done (Hastie, Chen, \& Smith, 2011).

\subsection{Evaluation Stage}

The evaluation stage usually focuses on evaluating ideas generated during the idea generation stage in order to ensure high-quality decisions. For online teaching, VLCs, and general e-learning environments, the evaluation stage focuses on how ideas and goals are accomplished and attempts to answer the effectiveness or degree to which the goals were achieved. First, it is helpful to discuss the nature of students' experiences in VLCs during this stage. Therefore, the evaluation stage focuses on criteria for evaluating ideas, discussing implications of possible decisions, and selecting solutions for the problem (Olaniran, 1994). There are three to four steps in the evaluation stage.

The first is establishing criteria where a teacher or instructor sets in motion the process or method that the evaluation process will be based upon. For instance, how will deep-level or critical-level thinking be measured? How does the learning environment and communication interaction in VLCs bring about desired learning among others? Following the criteria is analyzing or discussing implications of possible decision alternatives. According to the VIT perspective, this process involves two key responsibilities. The first responsibility is to identify the positives and negatives of each possible decision alternative (Hirokawa \& Rost, 1992) and, if at all possible, to discuss how the positives may help alleviate the negatives (Olaniran, 1994). The second step is to make the decision. In this stage the goal is to weigh the pros and cons of each possible decision and chose one that appears to be the optimal decision. One must be cognizant that no particular approach will hold all positives but must be willing to choose the approach that appears to be the best when both pros and cons have been carefully considered.

Mediating the flow of interaction is critical in VLCs or online learning environments to make sure students stay on track and refrain from non-productive interaction during the evaluation stage. Empirical evidence indicates that when instructors provide students with directions on argumentations, students are likely to be more on task and use more justification for their positions, rather than simply trading their opinions when this structure is absent (McAlister, Ravenscroft, \& Scanlon, 2004; 2006). In an experiment where instructors facilitated Socratic strategies and devil's advocacy in synchronous CMC (i.e., dialogue that moves or challenges students to justify their opinions), students developed and defended their arguments (Walker, 2004). In other words, the instructor's role as a facilitator does not mean passive observer. Instead, 
the instructor's role should be active and should encourage proactive participation that allows room for learners to learn in a manner commensurate with their cultural learning preferences. In essence, instructors' roles in VLCs require identification of learners' needs as well as the ability to utilize multiple strategies to deal with different students and their idiosyncratic cultural needs.

The basic question to navigate in the evaluation stage is how Web 2.0 helps or deters from learning. All activities of evaluation must be subjected to this key question. Hence, the idea of control must be addressed by instructors, facilitators, and learners on how to best answer the question. For instance, how can Facebook help increase effective learning from the standpoint of both instructors and learners? When examining Facebook interactions, Berg, Berquam and Christoph (2007) suggest that a careful consideration of "how students use social technologies can help [educators] build a strong network of information" and aid in how to "think differently about how [educators] communicate with students and with each other" (p. 44). Therefore, when incorporating Facebook into the Web 2.0 classroom, it is essential to focus learners' involvement and find ways to expand upon systems already in place.

Similarly, when utilizing social networking, core activities such as communication, teaching, tutoring, and study groups have their own unique needs that must be taken into consideration and incorporated into various interactive activities, such as those found on Web 2.0 (Anderson, 2003; Berg, Berquam \& Christoph, 2007; Olaniran, 2007; Picciano, 2001). For example, it has been suggested that for teacherstudent communication, instructors may utilize Facebook to help orient students to the learning environment (Olaniran \& Williams, 2010). At the same time, Web 2.0 can also be used to facilitate online icebreakers to help students get to know one another and assist instructors in getting to know their students (Olaniran \& Williams, 2010). Instructors can also create various student groups for group projects and use their own individual Facebook pages to offer more insight as to their interests and life pursuits. The Facebook wall can be used to facilitate discussion about upcoming assignments and to clarify any student concerns or questions. This functionality can also be used to provide students with a type of status check in regard to classroom schedules and alleviate confusion that may occur with the learning materials. Housekeeping or administrative duties such as teachers sending reminders to students about pending deadlines can also be accomplished within the VLCs.

For student-student interactions, students via Web 2.0 tools can connect with other students, view photos and other self disclosure information, and get to know one another based upon their online virtual identities. Furthermore, through the use of privacy settings in Facebook, students have the flexibility to decide how they grant access or share information with their classmates and instructors. This approach allows students to have certain control without negatively impacting teachers' control over learning content. Also, for increased and interactive learning, students can form teams for studying and completing projects or assignments with one another while allowing for real-time interactions (Olaniran \& Williams, 2010). As some scholars suggest, students are able to remind one another when deadlines are approaching and/or when assignments/grades are in jeopardy (Berg, Berquam, \& Christoph, 2007).

For student-content and instructor-content interactions, instructors can utilize Web 2.0 tools that allow students to explore, in depth, various aspects of the subject matter being taught through various online resources. For example, the provision of additional resources through tag links or other online sources as course material supplements is one avenue. Olaniran and Williams (2010) suggest that instructors can 
create problem scenarios and case studies with Web 2.0 in VLCs that require students to participate in online Web quests, field trips, and scavenger hunts to enhance students' learning and application of theoretical content and subject matter. Students in VLCs, with the aid of Web 2.0 tools, are also able to share results of personal research on certain topics with selected groups as a way to supplement instructor materials (Achterman, 2006; Jakes, 2006; Mejias, 2007; Olaniran \& Williams, 2010). In spite of the functionalities offered by social media within VLCs, there is however no guarantee students will use them, especially when the functionalities do not align with learners' personal learning preferences. This is why it is important that instructors become sensitive to learners' cultures and learning preferences.

With attention to the socio-cultural needs of learners, instructors must be proactive about learning goals, negotiating control, and accomplishing learning goals altogether. For instance, Poftak (2006) discussed the Elgg system, which is like Facebook in that it is user-driven, low-maintenance, and is wide open. However, Poftak (2006) points to the fact that it is impossible to satisfy everyone's needs with just one particular type of software. Perhaps one of the most important aspects of Elgg is recognition: not all forms of openness are good when it comes to learners' information and, as a result, the system's designers decided to add a plug-in module that offers extra privacy and administrative control for schools and users (see Poftak, 2007). Perhaps the hallmark of a good Web 2.0 tool is flexibility that allows instructors to identify key learning goals and to develop ways to accomplish them while balancing these goals with students' needs.

\section{Practical Implications}

One of the benefits of Web 2.0 is the assistance it could provide lifelong learners. Also, another benefit is the fact that it creates a forum and structure that emerges through collaborative participation, although the structure is always in the process of constant and continuous change. The technologies are able to adapt to the changing needs of learners and the group they serve (Dron, 2007). Specifically, social software that makes up Web 2.0 offers structure that is not confined to the boundaries of teachers and is believed to help circumvent, or reduce, the cost of traditional institutional learning while saving time. However, one must be careful because information readily available does not necessarily constitute valid information or authenticate that the information comes from a reliable source and comes with the assurance that the information has not been tampered with. Notwithstanding, Web 2.0 is here to stay and is a commonplace tool rooted in the social fabrics of our societies; hence, great care is needed in assessing information and quality of the accompanying information. Iif care is not taken, one might assume that the social software is an end in itself. To this end, proponents of Web 2.0 caution that Web 2.0, because of its structure, may not be useful pedagogically (e.g., Anderson, 2007; Dron, 2007; Mejias, 2005; 2007; Vassileva, 2004).

The danger to online learning is to approach it as a mere or simple duplication of face-to-face lectures in which technology is an appendage to education instead of playing a more transforming role (Olaniran \& Williams, 2010). For instance, this paper argues the role of culture in learning and, in particular, in VLCs. Thus, Web 2.0 technologies require users to put cultural needs and demands of their learners at the center of learning and to identify how to use technology tools to meet those needs. The issue of culture and control then presents significant challenges to e-learning and VLCs in the age of globalization (Olaniran, 2009; Olaniran \& Williams, 2010). For example, Rodrigues (2005) finds in a study of consisting of 310 participants that learners in a high-power distance culture 
clearly prefer passive methods, which uses techniques such as lectures, guest speakers, and formal presentations, over active learning, which opts for independent case studies and exploratory techniques. Hence, Rao (2011) suggests that high-power distance cultures may show preference for synchronous e-learning methods. Furthermore, Hrastinski (2008) observed that asynchronous media offers learners the capacity for self reflection and is more suitable for individualistic cultures that value self-paced learning over synchronous media. Rao (2011) also presents how Korean employees (i.e., highpower distance culture) were not able to discuss e-learning content even after they had completed learning modules. The same is true for Brazilians who indicated preference for a face-to face because the solitary learning style was inadequate for mastering course contents (Edmundson, 2009).

Consequently, culture and control in VLCs may hold different implications for different types of learning emphasis. For instance, learning environments emphasize different learning focuses such as student-group, teacher-student, content-student, and group-group/others (Olaniran, 2006; 2007).

\subsection{Student-Group}

The student-group environment describes a social software environment where learners are considered to be part of a group. Also, learners become part of the process and are products of influence. In this particular mode of interaction, students are able to influence one another's learning experiences and development. This approach may be more appealing to learners in individualistic and high-power distance cultures.

\subsection{Teacher-Student}

The teacher-student environment focuses on the central role of teachers in learning processes. In essence, teachers have to increasingly structure how learners receive information in VLCs. For example, teachers' roles may include determining learning goals and potential outcomes that are conducive to cultural preferences demonstrated and preferred by learners in high-power distance cultures.

\subsection{Content-Group}

The content-group environment focuses on the Web 2.0 tools creating structure that is not intended by users. The structure typically develops from members' behaviors in the group, which consequently affects individuals' actions as members of the group. From this standpoint, the group behavior is seen as a direct result of the content (Dron, 2007). Thus, VLC tools may be used to help unleash individual creativity. This is an approach that may be appealing to learners from individualistic cultures.

\subsection{Group-Group}

The group-group environment focuses on the open sources, or standards, that group members use to make the exchange of information simple and unequivocal. For example, multiple social software platforms (e.g., Google Maps, Flickr images, blogs, and others) can be used simultaneously to interconnect information and create greater levels of interconnectivity (i.e., community) among users, rather than one individual, or a socially static space. The direct implications include the attempt to use social media technologies to help attend to learners' needs for social support. 
What the Bola Ola method offers is an attempt to guide implementations of elearning in VLCs and in a way serves as a checklist of how to structure and accomplish desired learning goals while creating a culturally sensitive learning environment. A systematic step-by-step approach for designing learning and evaluating the learning processes will help those charged with the aim of channeling social media tools to harness culturally appropriate learning and human resources goals that are essential in a global environment.

\section{Conclusion}

Using emerging technologies to build a VLC requires adequate planning and consideration. The Bola Ola method is presented as a way to properly design and evaluate learning goals in VLCs and to offer guidelines for anticipating and addressing critical cultural challenges that impact learners in e-learning and VLCs and cooperatives. This is important, especially as there is an increasing use of social media in e-learning when these social media applications are not necessarily designed for learning purposes. The current paper discusses the role of culture in VLC development and technology applications that ultimately influence learning.

\section{References}

1. Anderson, T. (2007). Book Review-Control and constraint in e-learning: Choosing when to choose. International Review of Research in Open Distance Learning, 8(2), 1-3.

2. Aydin, C., McIsaac, M., \& Johari, A. (2004). The impact of instructional technology in Turkey. Educational Technology Research \& Development, 52(1), $105-112$.

3. Biech, E. (2008). Instructional design models and learning theories. ASTD Handbook for learning professionals. United Book Press Inc., Baltimore, MD, pp. 201-10

4. Bonk, C.J. (2009). The world is open: How Web technology is revolutionizing education. CA: Jossey-Bass.

5. Chhokar, J.S., Brodbeck, F.S., \& House, R.J. (2007). Culture and leadership across the world: The GLOBE book of in-depth studies of 25 societies. Mahwah, NJ: Lawrence Erlbaum.

6. DeSanctis, G., \& Poole, M.S. (1994). Capturing the complexity in advanced technology use: Adaptive structuration theory. Organization Science, 5(2), 121147.

7. Devereaux, M.O., \& Johansen, R. (1994). Global work: Bridging distance, culture, \& time. San Francisco, CA: Jossey-Bass.

8. Dron, J. (2007). Designing the undesignable: Social software and control. Educational Technology \& Society, 10(3), 60-71.

9. Dunn, P., \& Marinetti, A. (2007). Beyond localization: Effective learning strategies for cross-cultural e-learning. In A. Edmundson (Ed.), Globalized e-learning cultural challenges (pp. 255-266). NY: Idea Group.

10. Economides, A.A. (2008). Culture-aware collaborative learning. Multicultural Education \& Technology Journal, 2(4), 243-267. 
11. Edmundson, A.L. (2009). Culturally accessible e-learning: An overdue global business imperatives. Training \& Development, 63(4), 40-45.

12. Ess, C. (2002). Cultures in collision: Philosophical lessons from computermediated communication. Metaphilosophy, 33(1-2), 229-253.

13. Ess, C., \& Sudweeks, F. (2005). Culture and computer-mediated communication: Toward new understandings. Journal of Computer-Mediated Communication, 11(1), Accessed online from http://jcmc.indiana.edu/voll11/issue1/ess.html.

14. Fisher, B.A. (1980). Small group decision making, (2nd Edition). NY: McGrawHill.

15. Green, C., \& Ruhleder, K. (1995). Globalization, borderless worlds, and the tower of Babel: Metaphors gone awry. Journal of Organizational Change Management, $8(4), 55-68$.

16. Grooms, L.D. (2003). Computer-mediated communication: A vehicle for learning. The International Review of Research in Open and Distance Learning, 4(2). Retrieved from www.irrodl.org/content/v4.2/grooms.html.

17. Gudykunst, W.B., Chua, E., \& Gray, A.J. (1987). Cultural dissimilarities and uncertainty reduction processes. Communication Yearbook, 10, 456-469.

18. Hall, E.T. (1976). Beyond culture. New York: Doubleday.

19. Hastie, M., Chen, N.S., \& Smith, R. (2011). Negotiating content with learners using technology enhanced teaching and learning solutions. Knowledge Management \& E-Learning: An International Journal, 3(3), 412- 427.

20. Heaton, L. (2001). Preserving communication context: Virtual workspace and interpersonal space in Japanese CSCW. In C. Ess (Ed.), Culture, technology, communication: Towards an intercultural global village (pp. 213-240). Albany, NY: State University of New York Press.

21. Heaton, L. (1998). Preserving communication context: Virtual workspace and interpersonal space in Japanese CSCW. In C. Ess and F. Sudweeks (Eds.), Cultural attitudes towards communication and technology (pp. 163-186). Australia: University of Sydney Press.

22. Henning, E. (2003). I click therefore I am (not): Is cognition 'distributed' or is it 'contained' in borderless e-learning programs? International Journal of Training and Development, 7(4), 303-317.

23. Hofstede, G.H. (2001). Culture's consequences : Comparing values, behaviors, institutions, and organizations across nations. Thousand Oaks, CA: Sage.

24. Hofstede, G. (1983). Dimensions of national cultures in fifty countries and three regions. In J. Deregkowski, S. Dziurawiec, \& R. Annis (Eds.), Expiscations in cross-cultural psychology (pp. 335-355). Lisse, Netherlands: Swets \& Zeitlinger.

25. Hofstede, G. (1980). Culture's consequences. Beverly Hills, CA: Sage.

26. Hofstede, G., \& Bond, M. (1984). Hofstede's culture dimensions: An independent validation using Rokeach's value survey. Journal of Cross-Cultural Psychology, 15, 417-433.

27. Hossain, M., \& Aydin, H. (2011). A web 2.0 based collaborative model for multicultural education . Multicultural Education \& Technology Journal, 5(2), 116-128.

28. Hrastinski, S. (2008). Asynchronous and synchronous e-learning. Educause Quarterly, 31(4), 17-23. 
29. Jarvis, P. (2000). Globalization, the learning society, and comparative education. Comparative Education, 36(3), 343-355.

30. Khalil, O.E.M., \& Seleim, A. (2009). National culture practices and societal information dissemination capacity, (pp. 104-113). Proceedings of the 2009 Conference on Information Science, Technology, and Applications.

31. Lee, D., \& Johari, A. (2004). Web-based instruction in China: Cultural and pedagogical implications and challenges. Educational Technology Research \& Development, 52(1), 101-105.

32. McAlister, S., Ravenscroft, A., Scanlon, E. (2004). Combining interaction and context design to support collaborative argumentation using a tool for synchronous CMC. Journal of Computer Assisted Learning, 20, 194-204.

33. McConnell, S. (1998). NGOs and internet use in Uganda: Who benefits?. In C. Ess \& F. Sudweeks (Eds.), Cultural attitudes towards communication and technology (pp. 104-124). Australia: University of Sydney Press.

34. McSweeney, B. (2002). Hofstede's model of national cultural difference and their consequences: A triumph of faith - a failure of analysis. Human Relations, 55(1), 89-117.

35. Mejias, U. (2007). Teaching social software with social software. Innovate: Journal of Online Education, 2(5).

36. Mesdag, M.V. (2000). Culture sensitive adaptation or global standardization - the duration of usage hypothesis. International Marketing Review, 17, 74-84.

37. Nathan, E. (2008). Global organizations and e-learning: Leveraging about learning in different cultures. Performance Improvement, 47(6), 18-24.

38. Olaniran, B.A. (2009). Discerning culture in e-learning and knowledge management in the global workplace. Knowledge Management \& E-Learning: An International Journal, 1(3), 180-195.

39. Olaniran, B.A. (2007). Challenges to implementing e-learning in lesser-developed countries. In A. Edmundson (Ed.), Globalized e-learning cultural challenges (pp. 18-34). Hershey, PA: Idea Group.

40. Olaniran, B.A. (2006). Applying synchronous computer-mediated communication into course design: Some considerations and practical guides. Campus-wide Information Systems, 23(3), 210-220.

41. Olaniran, B.A. (2001). The effects of computer-mediated communication on transculturalism. In V. Milhouse, M. Asante, \& P. Nwosu (Eds.), Transcultural realities (pp. 83-105). Thousand Oaks, CA: Sage.

42. Olaniran, B.A. (1994). Group performance and computer-mediated communication. Management Communication Quarterly, 7, 256-281.

43. Olaniran, B.A., \& Agnello, M.F. (2008). Globalization, educational hegemony, and higher education. Multicultural Education \& Technology Journal, 2(2), 68-86.

44. Olaniran, B.A., \& Agnello, M.F. (2008). Globalization, educational hegemony, and higher education. Journal of Multicultural Educational Technology, 2(2), 68-86.

45. Olaniran, B.A., \& Stewart, R.A. (1996). Instructional practices and classroom communication apprehension: A cultural explanation. Communication Reports, 9, 193-203.

46. Olaniran, B.A., \& Williams, I. M. (2010). Web 2.0 and learning: A closer look at transactional control model in e-learning. In N. Lambropoulos \& M. Romero (Eds.), 
Educational social software for context-aware learning: Collaborative methods and human interaction (pp. 23-37). Hershey, PA: Information Science Reference.

47. Poole, M.S. (1981). Decision development in small groups: A comparison of two models. Communication Monographs, 48, 1-24.

48. Rao, P. (2011). E-learning in India: The role of national culture and strategic implications. Multicultural Education \& Technology Journal, 5(2), 129-150.

49. Roach, K.D., \& Olaniran, B.A. (2001). Intercultural willingness to communicate and communication anxiety in international teaching assistants. Communication Research Reports, 18, 26-35.

50. Rodrigues, C. (2005). Culture as a determinant of the importance business level students place on ten teaching/learning techniques: A survey of university students. Journal of Management Development, 24(7/8), 608-622.

51. Sanchez-Franco, M.J., Martinez-Lopez, F.J., \& Martin-Velicia, F.A. (2009). Exploring the impact of individualism and uncertainty avoidance in web-based electronic learning: An empirical analysis in European higher education. Computers \& Education, 52, 588-598.

52. Schneckenberg, D. (2009). Understanding the real barriers to technology-enhanced innovation in higher education. Educational Research, 51(4), 411-424.

53. Shepard, L. (2010). The role of assessment in a learning culture. Educational Researcher, 29(7), 4-14.

54. Sitkin, S.B., Sutcliffe, K.M., \& Barrios-Choplin, J.R. (1992). A dual capacity model of communication media choice in organizations. Human Communication Research, 18, 563-598.

55. Smith, P.B. (2002). Culture's consequences: Something old and something new. Human Relations, 55(1), 119-135.

56. Solomon, C.M. (2001). Managing virtual teams. Workforce, 80(6), 60-65.

57. Stewart, V., \& Kagan, L. (2005). Conclusion a new world view: Education in a global era. Phi Delta Kappan, 87(3), 241-245.

58. Tapanes, M.A., Smith, G.G., \& White, J.A. (2009). Cultural diversity in online learning: A study of the perceived effects of dissonance in levels of individualism/collectivism and tolerance of ambiguity. Internet and Higher Education, 12, 26-34.

59. Thurber, B.D., Pope, J.W., \& Stratton, J. (2003). Computer, telecommunications and Western culture. Retrieved September 24, 2009, from, http://www.hoboes.com/html/NetLife/CRIT/CWC.html.

60. Van Dam, N., \& Rogers, F. (2002, May). E-learning cultures around the world: Make your globalized strategy transparent. E-learning (www.elearningmag.com), 28-33.

61. Walker, S.A. (2004). Socratic strategies and devil's advocacy in synchronous CMC debate. Journal of Computer Learning, 20, 172-82.

62. Zhu, C., Valcke, M., \& Schellens, T. (2009). A cross-cultural study of online collaborative learning. Multicultural Education and Technology Journal, 3(1), 3346. 